\title{
Ureteral Calcinosis in Juvenile Dermatomyositis. Successful Precocious Surgical Management
}

\author{
Ricardo J. Duarte, Francisco T. Denes, Adriana M. Sallum \\ Divisions of Urology and Rheumatology, University of Sao Paulo Medical School, USP, Sao Paulo, \\ Brazil
}

\begin{abstract}
We report a successful surgical intervention to repair bilateral ureteral strictures in a child with juvenile dermatomyositis (JDM) and ureteral calcinosis. This is the fourth reported case in medical literature. A 9-year-old-girl with severe JDM, a rare connective tissue disease characterized by skin and muscles vasculitis, was under immunosuppressive therapy. In the course of the disease, she presented recurrent urinary tract infections. Bilateral ureteral dilation was detected by ultrasound (US) and intravenous pyelogram (IVP). CT scan showed bilateral ureteral calculus. Ureteroscopy revealed bilateral ureteral calcinosis, confirmed by histopathological analysis. Bilateral double-J stents were placed, resulting in transient improvement of ureteral dilation and infection, but only the surgical removal of abnormal ureteral portions was successful. In conclusion, endourological approach is recommended for diagnosis of urinary tract involvement by JDM because radiological evaluation can be misleading. The immunosuppressive treatment and the resection of damaged ureteral segments have allowed the control of urinary complications.
\end{abstract}

Key words: ureter; calcinosis; dermatomyositis; ureteroscopy

Int Braz. J Urol. 2006; 32: 574-7

\section{INTRODUCTION}

Urinary tract involvement in juvenile dermatomyositis (JDM) is an uncommon and challenging disease to treat. We report the first case with no surgical complications and successful outcome.

\section{CASE REPORT}

A 9-year-old girl with JDM, receiving prednisone, cyclosporine-A and methotrexate, presented recurrent urinary tract infections and bilateral pieloureteral dilation in ultrasonography. IVP revealed a radiopaque left upper ureteral lesion and bilateral ureteral dilation near the iliac vessels with distal obstruction, more evident at the right side. A computed tomography (CT) scan diagnosed a left upper and mid ureteral calculus, and another in the right mid ureter (Figure-1).

The child was first submitted to a right side ureteroscopy, because it was the most dilated side. It revealed no calculus in the lumen, but the ureteral wall showed calcifications. Biopsy showed an inflammatory process with dystrophic calcifications and mucosal ulceration (Figure-2). 

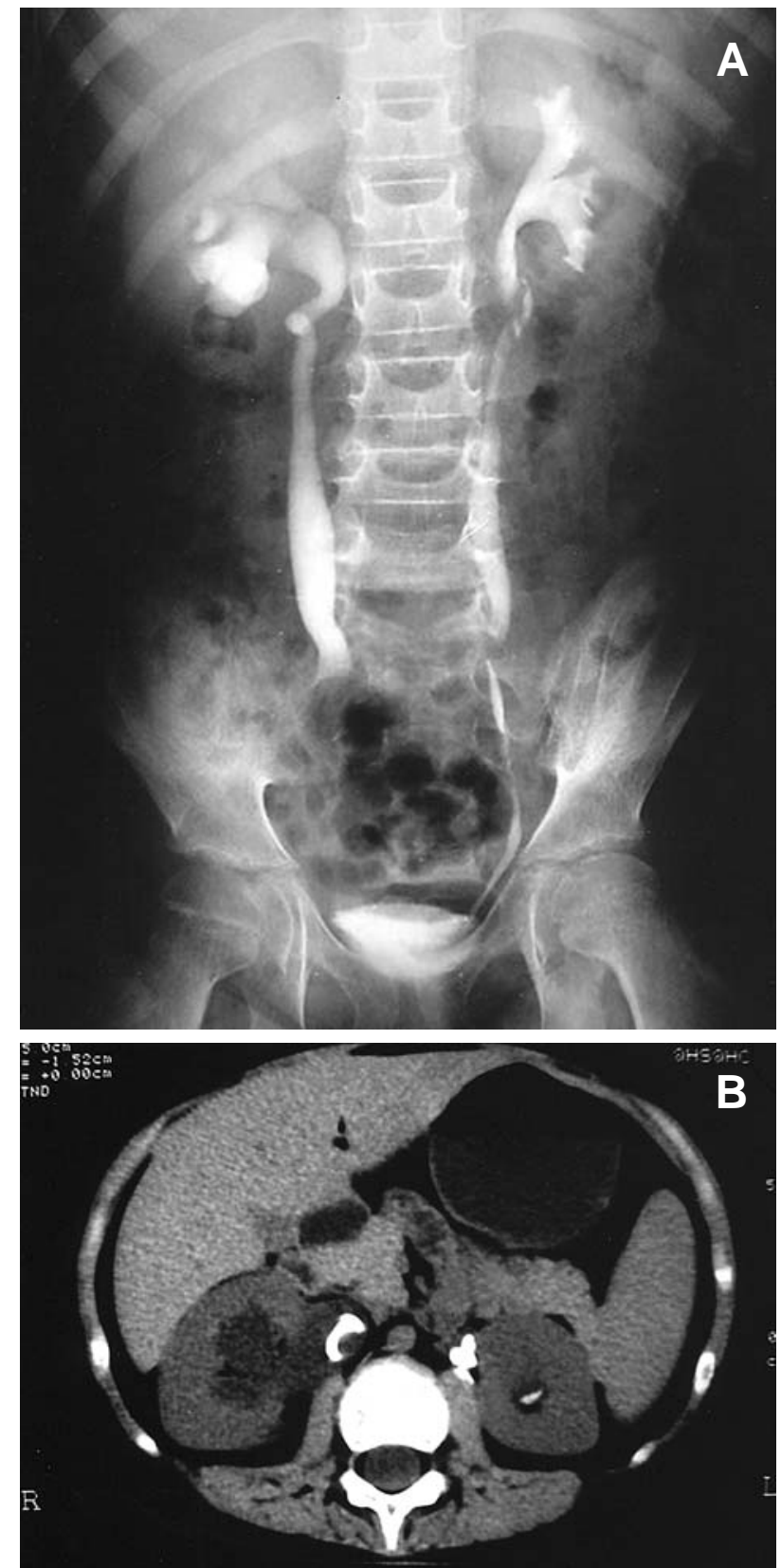

Figure 1- Juvenile dermatomyositis. A) Preoperative intravenous pyelogram revealing bilateral ureteral dilation. B) Preoperative CT scan showing bilateral "ureteral calculus", misdiagnosing ureteral calcification.

Bilateral double-J stents were placed improving ureteral dilation. Periodical substitution of the stents was scheduled, but the replacement of the left stent was not possible due to non-progression of the guide wire. Surgery was then indicated (left subcostal lombotomy). The left upper ureter was calcified and attached to the psoas muscle. A $2 \mathrm{~cm}$ calcified segment was then removed followed by termino-terminal anastomosis and double-J placement. The left mid segment and the right ureter were untouched since they were considered satisfactorily pervious and a conservative management was chosen. Histopathological findings were similar to previous biopsy.

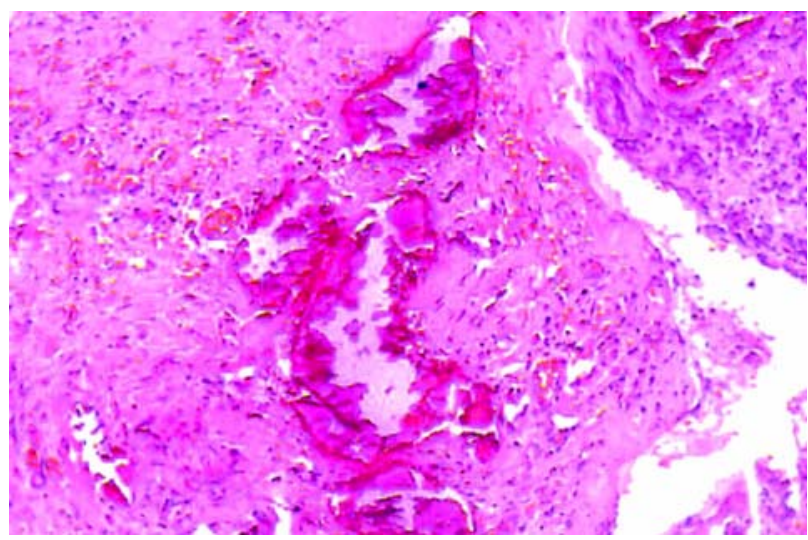

Figure 2 - Microscopy of removed ureter. Note inflammatory infiltrate involving the ureteral muscular wall with widespread calcifications (HE, X100).

Two months later, a $2 \mathrm{~cm}$ calcified segment of the lower right ureter was resected near the iliac vessels and a termino-terminal anastomosis was performed through a right extended infraumbilical transverse incision. The left stent was then removed and, after a retrograde ureteropyelogram, we considered the left ureter pervious and decided to keep it under observation. Chronic ureteritis with urothelial hyperplasia and fibrous thickness of mucosa and submucosa were observed in the removed portion.

The child did well, without urinary tract infections, dilation or complications. Postoperative IVP and CT scan (Figure-3) revealed a slight left ureteral enlargement without clinical implications and small calcification in the left psoas muscle. 


\section{Ureteral Calcification in Juvenile Dermatomyositis}
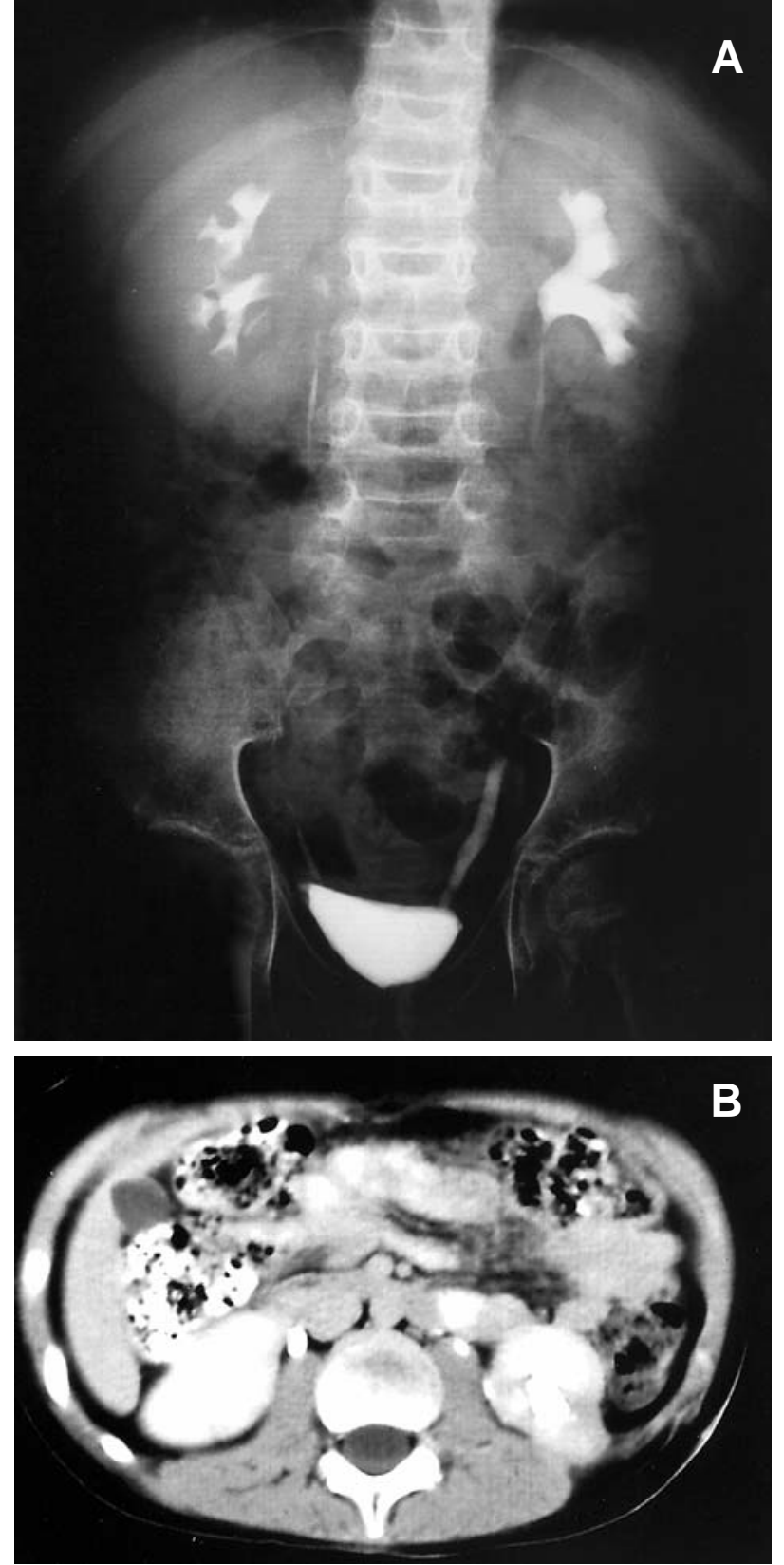

Figure 3-Juvenile dermatomyositis. A) Postoperative intravenous pyelogram revealing satisfactory urinary flow without ureteral dilation. B) Postoperative CT scan revealing a small calcification in the left psoas muscle and left ureter, without dilation.

\section{DISCUSSION}

Urinary tract involvement in JDM is rarely reported. Borrelli et al. (1) have described a child with
JDM and bilateral ureteral necrosis, with bad evolution and death due to the disease. Bléry et al. (2) and Le Guillou et al. (3) have reported the same situation, with surgical complications such as stenosis and fistula.

Considering that JDM is an inflammatory process, the early introduction of immunosuppressive agents and control of the disease, associated to a careful periodic urological evaluation and precocious surgical treatment, have resulted in the successful outcome of our patient.

The image methods misdiagnosed lithiasis. Only ureteroscopy and ureteral biopsy disclosed the diagnosis of calcinosis. Although radiological evaluation was suggestive of lithiasis, it was a good decision not to insist with endourological procedures. Surgical resection of the damaged segment was efficient, with normalization of urinary flow without complications.

\section{CONCLUSION}

Children with JDM and recurrent fever should be submitted to urinary tract evaluation, but the image methods can be unclear. In this case, ureteroscopy disclosed the diagnosis, but did not solve the problem. Precocious resection of the damaged ureteral segments has improved the obstructive problem and allowed urinary tract infection control. These remarks can be useful to the management of similar cases.

\section{CONFLICT OF INTEREST}

None declared.

\section{REFERENCES}

1. Borrelli M, Prado MJ, Cordeiro P, Wroclawski ER, Monteiro Junior J, Kiss MH, et al.: Ureteral necrosis in dermatomyositis. J Urol. 1988; 139: 1275-7.

2. Blery M, Lacert P, Touboul A: Lithiasis and bilateral necrosis of the ureters occurring during 


\section{Ureteral Calcification in Juvenile Dermatomyositis}

dermatomyositis. A definite entity or a coincidence? J Radiol Electrol Med Nucl. 1978;59: 279-82.
3. Le Guillou M, Richard F, L'Henaff F, Ferriere JM, Durand J, Lacert P, et al.: Bilateral ureteral necrosis in a child with dermatomyositis. Eur Urol. 1980; 6: 190-1.

Accepter after revision:

April 17, 2006

Correspondence address:

Dr. Ricardo Jordão Duarte

Rua Afonso Brás 525 / 82

04511-011, São Paulo, SP, Brazil

E-mail: ricjordao@uol.com.br 